\title{
PROCESSO DE SECAGEM DA GLÂNDULA MAMÁRIA DE BOVINOS DA RAÇA HOLANDESA: AVALIAÇÃO DASCARACTERÍSTICAS MICROBIOLÓGICAS DA SECREÇÃO LÁCTEA DURANTE O PERÍODO SECO
}

\section{D.B. Birgel, E.H. Birgel Junior, F.C. Pogliani, R.F.S. Raimondo, E.H. Birgel, W.P. Araújo}

Universidade deSão Paulo, Faculdade de Medicina Veterinária eZootecnia, Departamento deClínica Médica, Centro de Pesquisa e Diagnóstico de Enfermidades de Ruminantes, Av. Prof. Dr. Orlando Marques de Paiva, 87, CEP 05508-270, São Paulo, SP, Brasil. E-mail: dabirgel@usp.br

\section{RESUMO}

\begin{abstract}
Com o objetivo de avaliar as características microbiológicas da secreção láctea durante o processo de secagem da glândula mamária de vacas da raça Holandesa, foram colhidas amostras de 44 mamas na última ordenha antes do início do processo de secagem, durante a evolução do processo de secagem $\left(1^{\circ}, 3^{\circ}, 5^{\circ}, 7^{\circ}, 10^{\circ}, 15^{\circ}, 30^{\circ}\right.$ e $45^{\circ}$ dia do período seco) e no retorno à lactação. Após os primeiros jatos de secreção láctea terem sido desprezados, procedeu-se a sua colheita asséptica, para ser utilizada no exame microbiológico. No retorno da lactação observou-se que a frequência de isolamento bacteriano $(46,15 \%)$ foi significantemente menor do que o encontrado durante o período seco. Entre a última ordenha antes do início do processo de secagem e o $45^{\circ}$ dia do período seco não houve diferenças estatísticas entre as frequências de isolamentos bacterianos que oscilaram entre $72,73 \%$ e $84,09 \%$. Os principais gêneros bacterianos isolados foram Staphylococcus spp., Corynebacterium spp. e Streptococcus spp. A análise da dinâmica da população bacteriana durante o período seco permitiu afirmar que a taxa de cura das infecções existentes foi igual a 40,63 \%, enquanto as taxa de novas infecções e re-infecções durante o período seco foram, respectivamente, iguais a $66,67 \%$ e $61,54 \%$.
\end{abstract}

PALAVRAS-CHAVE: Leite, período seco, características microbiológicas, bovino, raça Holandesa.

\section{ABSTRACT}

THE INVOLUTION OF THE MAMMARY GLANDIN HOLSTEIN COWS: EVALUATIONOF THE MICROBIOLOGICAL CHARACTERISTICS OF THE LACTEAL SECRETION IN THE DRY PERIOD. In order to evaluate the microbiological characteristics of the lacteal secretion in the involution of the mammary gland of Holstein cows, examination was made of 44 udders at last milking before the dry period, during the dry period $(1,3,5,7,10,15,30$ and 45 days of the dry period), as well as the return to lactation. After discarding the first jets of the lacteal secretion, the samples for the microbiological analysis were aseptically collected. The percentage of bacteria isolated from the udders was lower on the return to lactation $(46.15 \%)$ than during the involution of the mammary gland. There was no statistical difference between the frequency of bacteria isolated from the last milking and from the 45 th day of the dry period isolations that oscillated between $72.73 \%$ and $84.09 \%$. The rate of cure of the infections in the dry period was $40.63 \%$, while the rate of new infections and reinfection were, respectively, $66.67 \%$ and $61.54 \%$.

KEY WORDS: Milk, dry period, microbiological characteristics, bovine, Holstein breed.

\section{INTRODUÇÃO}

Nos bovinos de leite existe a necessidade da glândula mamária ser submetida a um período de descansoentre duaslactações, pois, sem este período, há uma sensível redução da produção na lactação seguinte (Foley et al., 1972; OlIVER; SORDILLO,1988). Neste período, que se convencionou chamar de período seco, a ordenha é suspensa durante algumas semanas antes do parto. A não retirada do leite produzido pela glândula mamária desencadeia o processo fisiológico de sua involução, com drástica redução da produção de leite e sua reabsorção evidenciada por alterações nas características físico-químicas e celulares da secreção (SMITH; TODHUNTER, 1982). Essas mudanças podem interferir de maneira positiva ou negativa na ocorrência de novas infecções da glândula mamária (SMITH; TODHUNTER, 1982). 
A análise da literatura sobre a dinâmica das infecções intramamárias evidenciam que a incidência de novas infecções durante o período seco varia entre 6 e 45,7\% (BROWNing et al., 1990; EBERHART, 1982; McDonALD, 1982; NATZKe et al., 1975; NeAve etal.,1950; OLIVER et al., 1956), enquanto as taxas de cura de infecções nesse período variam entre 50,0 e 81,8\% (Rindsig et al., 1978; CUMMINS; MCCASKEY, 1987).

Apesar de não ter sido, ainda, determinada de forma definitiva as frequências da incidência de infecções da glândula mamária no período seco na pecuária leiteira do Brasil, resultados de pesquisas pioneiras como as apresentadas por PRIETO (1993) e Costa et al. (1994) revelaram, em levantamentos epidemiológicos, não ocorrer aumento do número de quartos infectados na secagem, mas, ao contrário, a diminuição, baseando-se essa conclusão na comparação da porcentagem de quartos infectados durante a lactação e a obtida no período seco.

Costa et al. (1994), em seu experimento, descreveram que durante a lactação 79,9\% dos quartos estavaminfectados, enquanto que, no períodoseco,70,6\% dos quartos estavam infectados. PRIETO (1993) constatou que $67,5 \%$ (106/157) das glândulas estavam infectadas na fase final da lactação, enquanto que no período seco, entre sete e dez dias após a interrupção da lactação, apenas 59,5\% (91/153) das glândulas encontravam-se nesta situação, ressaltando que sete a dez dias após o parto a porcentagem de glândulas infectadas era praticamente a mesma observada no período da secagem, ou seja, 57,5\% (77/134).

Ao consultar a literatura brasileira, verificou-se a necessidade do delineamento de estudos brasileiros com o intuito de avaliar a dinâmica das infecções intramamárias noperíodo seco. Desta forma a presente pesquisa teve a finalidade de avaliar as características microbiológicas da secreção láctea durante o processo de secagem da glândula mamária de bovinos da raça Holandesa, criados no Estado de São Paulo.

\section{MATERIALEMÉTODOS}

Na presente pesquisa foram utilizados 44 quartos mamários de vacas da raça Holandesa, no terço final de gestação, ou seja, todas as vacas encontravam-se em fase final de lactação (período variando entre 270 e 370 dias). Esses animais foram criados e mantidos em uma propriedadeleiteira localizada na Cidade de Paraibuna, região Sudoeste do Estado de São Paulo, sendo que as vacas selecionadas produziam, na fase final da lactação, entre 4 e 8 litros de leite por dia, retirados em duas ordenhas diárias. Antes da ordenha mecânica, os procedimentos rotineiros delimpeza dos tetos das vacas eram realizados com água, seguidos de secagem com toalhas de papel. Após a ordenha, os tetos eram mergulhados em uma solução antisséptica à base de iodo.

A seleção dos animais / mamas foi baseada no seu histórico, não sendo utilizados aqueles que apresentaram episódios recorrentes de mamite, ou que receberam qualquer medicação intramamária, há pelo menos dois meses antes do início do experimento. Na seleção foram excluídas as glândulas mamárias que apresentassem alterações das características macroscópicas do leite, como presença de grumos e/ ou alterações da cor do leite, detectadas na prova do fundo escuro; e que, na palpação da glândula mamária realizada, após a ordenha, apresentassem alterações de consistência que pudessem estar relacionadas à existência de quadro de mamite, conforme as recomendações de BIRGEL (1982).

Interrompeu-se a ordenha de forma abrupta e sem a utilização de terapia por via intramamária, com antibióticos de largo espectro e de longa duração ("terapia da vaca seca"), dando início ao processo de secagem da glândula mamária que passaram a ter amostras de secreção láctea colhidas para as análises microbiológicas nos momentos descritos na Tabela 1.

Tabela 1 - Constituição do grupo experimental para avaliar as características microbiológicas da secreção láctea durante o período seco de bovinos da raça Holandesa.

\begin{tabular}{|c|c|c|c|}
\hline \multicolumn{3}{|c|}{ Momentos de colheita } & \\
\hline \multicolumn{3}{|c|}{$\begin{array}{l}1 \text { Última ordenha antes do início do } \\
\text { processo de secagem }\end{array}$} & 44 \\
\hline \multirow{8}{*}{\multicolumn{2}{|c|}{ 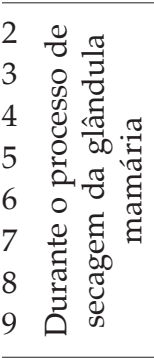 }} & $1^{\circ}$ dia do período seco & 44 \\
\hline & & $3^{\circ}$ dia do período seco & 44 \\
\hline & & $5^{\circ}$ dia do período seco & 44 \\
\hline & & $7^{\circ}$ dia do período seco & 44 \\
\hline & & $10^{\circ}$ dia do período seco & 44 \\
\hline & & $15^{\circ}$ dia do período seco & 44 \\
\hline & & $30^{\circ}$ dia do período seco & 44 \\
\hline & & $45^{\circ}$ dia do período seco & 44 \\
\hline & & No retorno à lactação & 26 \\
\hline
\end{tabular}

Antes da colheita das amostras fazia-se a antissepsia da extremidade do teto, particularmente do orifício do teto, utilizando-se um chumaço de algodão embebido em álcool 70\% e, a seguir, desprezava-se os primeiros jatos de leite ou secreção láctea, para então realizar a colheita do material destinado ao exame microbiológico, usando frascos plásticos estéreis com capacidade para $5 \mathrm{~mL}$ de leite. 
As amostras de secreção láctea foram semeadas em meio deágar-sangue meio de Edwards eincubadas a $37^{\circ} \mathrm{C}$, sendo a avaliação para a identificação das bactérias realizadas com 24, 48 e 72 horas após a semeadura. Após 24 horas deincubação, procedeu-se à identificação dos gêneros das bactérias que apresentaram crescimento no meio deágar-sangue, sendo a identificação baseada nos resultados do exame bacterioscópico e do teste de catalase.

As bactérias classificadas como pertencentes ao gênero Staphylococcus foram submetidas ao teste de coagulase em plasma de coelho e ao Staphy-Test ${ }^{\circledR}$ (diferencia o Staphylococcus aureus das demais espécies de Staphylococcus). Complementando o exame bacteriológico, passadas 48 e 72 horas de incubação, procedeu-se a nova avaliação das culturas que apresentaram crescimento no meio de ágar-sangue, sendo objetivo principal desta avaliação a identificação das bactérias do gênero Corynebacterium. A identificação das espécies bacterianas foi realizada para os gêneros Stapylococcus e Streptococcus, não sendo realizada para o gênero Corynebacterium por dificuldades de se estabelecer uma metodologia que oferecesse uma identificação confiável para este grupo de bactérias. Para a identificação de espécies do gênero Staphylococcus utilizou-se a prova da urease, a prova de redução do nitrato, prova de metabolização da arginina e fermentação dos seguintes açúcares: trealose, manitol, manose, xilose, maltose, lactose, sacarose e rafinose. Para a identificação de espécies do gênero Streptococcus utilizou-se a prova de hidrólise da esculina, Prova de CAMP, crescimento bacteriano a $45^{\circ} \mathrm{C}$, crescimento em $\mathrm{NaCl}$ a $6,5 \%$, prova de hidrólise do hipurato, prova de metabolização da arginina e fermentação dos seguintes açúcares: trealose, manitol, lactose e rafinose. As técnicas utilizadas para identificação e diferenciação das espécies bacterianas foram realizadas segundo as recomendações de LENNETTE et al. (1985) e COWAN; STEEL (1985), sendo os resultados obtidos comparados com os resultados presentes em tabelas de identificação bacteriana do Bergey’s Manual of Systematic Bacteriology (Holt et al., 1994).

A análise estatística dos resultados obtidos no exame microbiológico foi realizada seguindo as recomendações de BERQUó et al. (1981), sendo utilizado o teste de Duas Proporções, com níveis de significância menor ou igual a $5 \%$.

\section{RESULTADOSEDISCUSSÃO}

Em rebanhos paulistas, a prevalência de isolamento bacteriano em amostras de leite obtidas de mamas que não apresentavam alterações evidenciadas pelo exame físico do úbere, principalmente, pela consistência do parênquima, aspecto e cor da secreção, oscilava entre 50 e 70\% (ARAUJO, 1994; BIRGEL Junior, 2006; Costa et al., 2001; Della LiBera, 1998; PRIETO, 1993), sendo esses percentuais similares àqueles encontrados nesta pesquisa. Conforme apresentadona Figura 1, no retorno da lactação observou-se que a frequência de isolamento bacteriano (46,2\% - 12/26) foi estatisticamentemenor do que o observado durante o processo de secagem da glândula mamária. Durante o período seco o percentual de isolamento bacteriano oscilou entre $72,73 \%(32 / 44)$ e $84,09 \%$ (37/44).

Apesar de encontrar-se na literatura inúmeras pesquisas nas quais foi demonstrado que a incidência de infecções durante o período seco da mama era maior do que a detectada durante a lactação (McDonald; ANDERSON, 1981; NAtZKe, 1981; NeAVE $e t$ al.,1950; SMITH; TODHUNTER, 1982). Os resultados desta pesquisa não evidenciaram diferenças no percentual de isolamento bacteriano em amostras de leite colhidas entre a última ordenha do início do processo de secagem e $45^{\circ}$ dia do período seco (Fig. 1). Da mesma forma, CosTA et al. (1994) e PRIETO (1993) não puderam demonstrar aumento no percentual de quartos infectados durante o período seco.

Relativo aos agentes bacterianos encontrados na secreção láctea durante o período seco (Fig. 2), verificou-se que as bactérias mais frequentemente isoladas foram as do gênero Staphylococcus $(45,34 \%)$ e as do gênero Corynebacterium (43,17\%), sendo que as do gênero Streptococcus $(10,25 \%)$ foram isoladas com menor frequência. Em 1,24\% dessas secreções puderam ser isoladas associações de bactérias do gênero Staphylococcus e do gênero Streptococcus. Esses resultados estão em concordância com as referências consultadas e apontam, independentemente da fase da lactação e da condição da saúde da mama, ser os três referidos gêneros debactérias os principais agentes etiológicos das mamites dos bovinos (BERRY; Hillerton, 2002; Browning et al., 1990; Cummins; MCCASKEY, 1987; EBERHART, 1982; NATZKE et al., 1975; Neave et al., 1950; Oliver; Sordillo, 1988; Prieto, 1993; Rindsig et al., 1978; SMIth; TodHUnTER, 1982; ZADOKs et al., 2001).

Nas 162 amostras nas quais foram isoladas bactérias do gênero Staphylococcus observou-se a ocorrência das seguintes espécies: Staphylococcus intermedius (em 82,67\% - 124/150 das amostras), Staphylococcus chromogenes (em 12,00\% - 18/150 das amostras), Staphylococcus warneri (em 4,67\% - 7/150 das amostras), Staphylococcus arletae (em 0,66\% - 1/150 das amostras). Nas 40 amostras, nas quais foram isoladas bactérias do gênero Streptococcus, observou-se a ocorrência das seguintes espécies: Streptococcus bovis (em $91,89 \%$ - 34/37 das amostras) e Streptococcus dysgalactiae (em 8,11\% - 3/37 das amostras). 


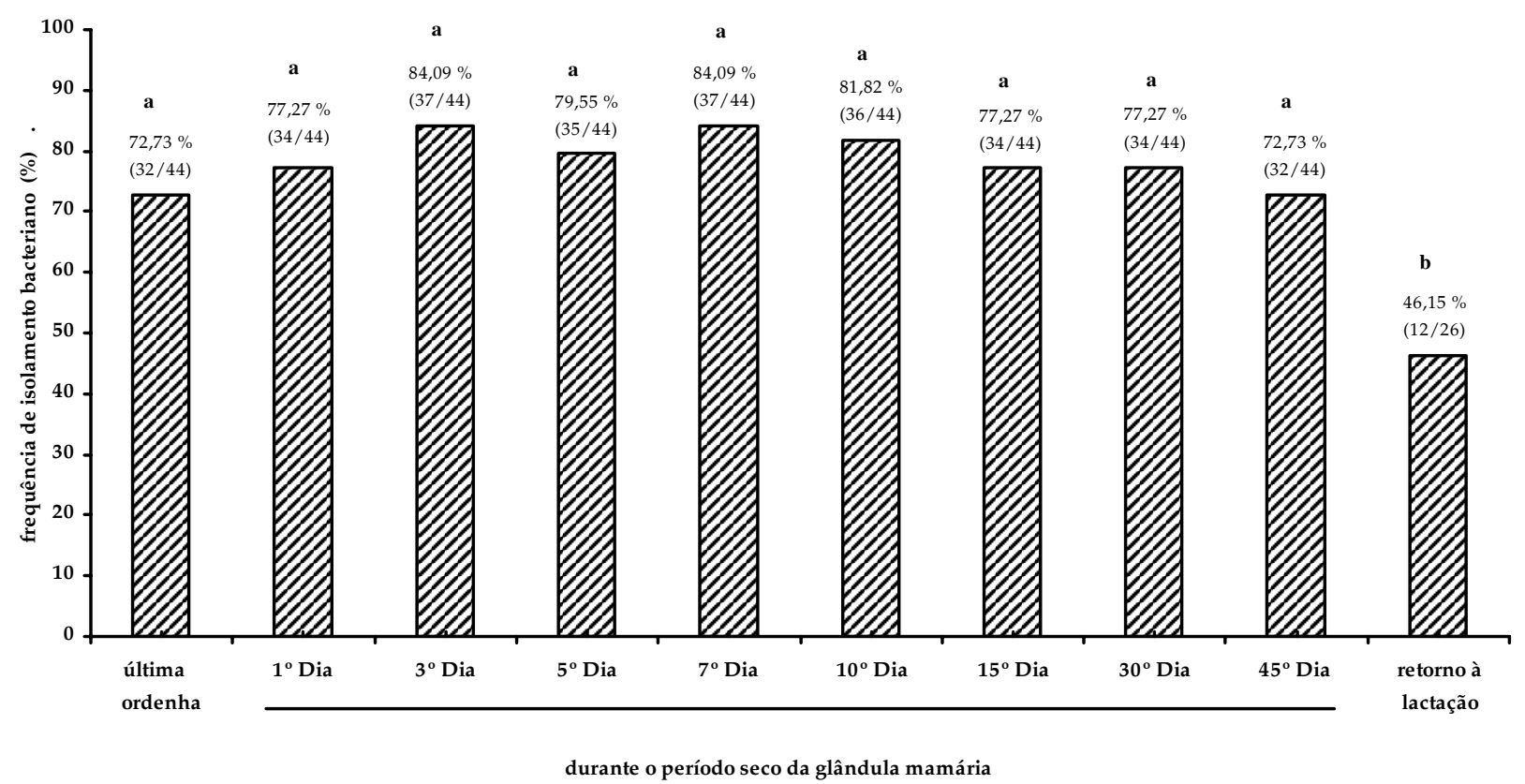

$\mathrm{ab}$ - letras não coincidentes significam diferença estatística significante $(\mathrm{p} \leq 0,05)$

Fig. 1 - Avaliação da influência do processo de secagem da glândula mamária na frequência de isolamento bacteriano na secreção láctea de bovinos da raça Holandesa.

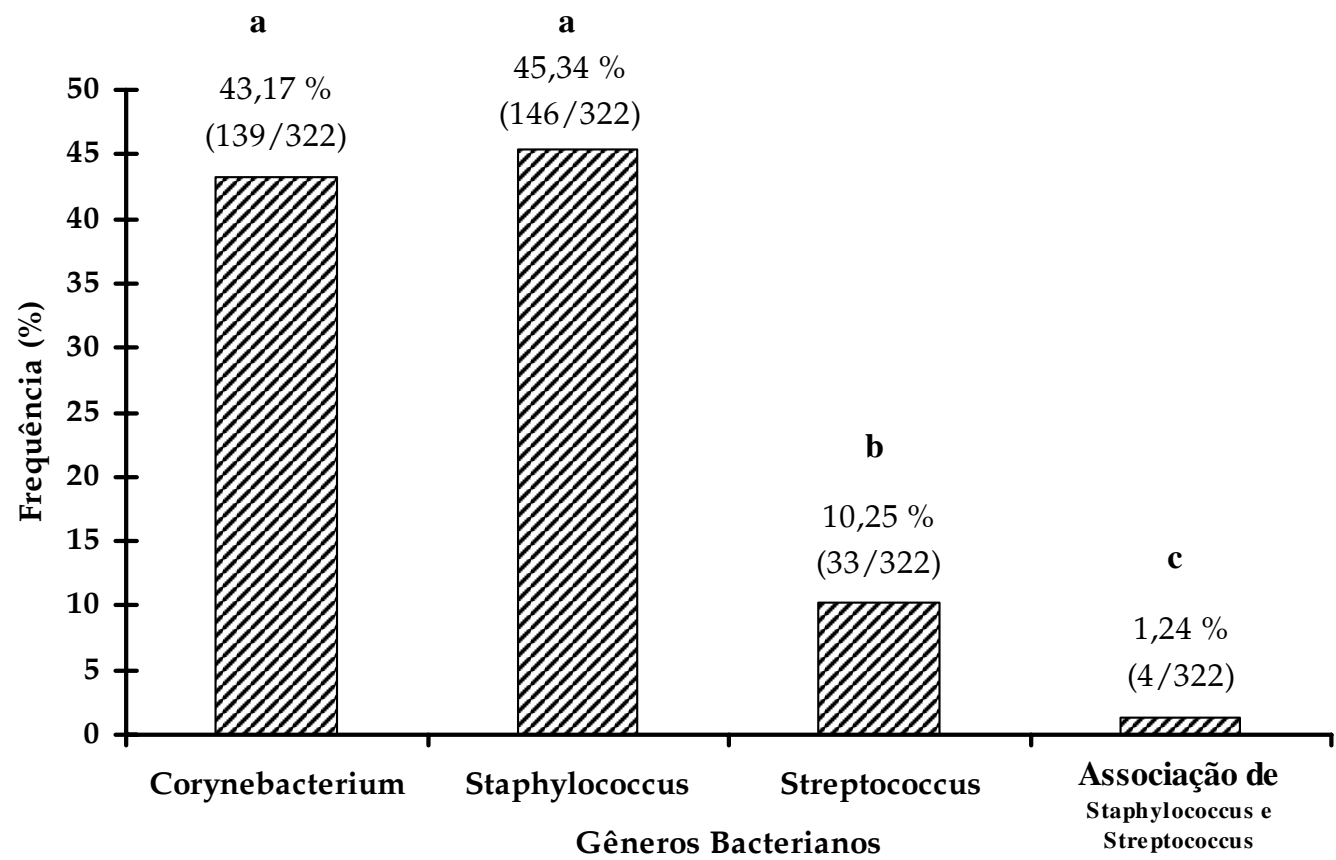

abc - letras não coincidentes significam diferença estatística significante $(\mathrm{p} \leq 0,05)$

Fig. 2 -Frequência de isolamento bacteriano na secreção láctea de bovinos da raça Holandesa, distribuídos segundo o gênero da bactéria, durante o processo de secagem da glândula mamária e no retorno à lactação.

É importante salientar que a presença dos agentes infecciosos na glândula mamária poderia ocorrer de forma fugaze epassageira determinando reações orgânicas mínimas. Em outros casos, poderia determinar, efetivamente, a difusão da colonização bacteriana nos tecidos mamários, sendo a presença do microorganismo persistente e duradoura, originando uma infecção e determinando reações orgânicas mais se- 
veras associadas a alterações do parênquima glandular. Os limites entre infecção e doença não seriam perfeitamente delimitados, podendo sofrer variação na dependência da metodologia e técnicas do pesquisador, como também dos seus critérios mais ou menos rígidos na avaliação dos resultados obtidos. Segundo as observações de BIRGEL JunIOR (2006), menos de 25 \% das amostras deleite com isolamentobacterianoapresentaram alterações dos elementos constitucionais das características físico-químicas e celulares, que permitiriam concluir que a mama estava doente.

Durante o período seco bactérias do gênero Corynebacterium e os Staphylococcus coagulase negativo não foram consideradas nocivas para o tecido glandular por diversos autores (BERRY; HILLERTON, 2002; BROWNING et al., 1990; CUMMINS; MCCASKEY, 1987; OlIVER;SORDILlO, 1988; RINDSIG et al., 1978;ZADOKs et al., 2001), sendo que CUMMINs; McCASKEY (1987) não observaram, no retornoà lactação, alterações no número de células somáticas ou diminuição na produção de leite de glândulas mamárias infectadas por Corynebacterium sp. durante o processo de secagem. BROWNING et al. (1990) e ZADOKS et al. (2001) consideraram, inclusive, que a presença de bactérias do gênero Corynebacterium teria uma ação protetora da mama contra agentes de maior patogenicidade como o $S$. aureus.

A avaliação dos resultados obtidos nos exames microbiológicos permitiu ainda que fossem efetuadas as observações a seguir discriminadas:

- constatou-se que 33,33\% (4/12) dos quartos permaneceram sem que qualquer agentebacteriano pudesse ser isolado durante todo o período seco estudado, enquanto em $66,67 \%$ (8/12) dos quartos foi possível o isolamento de bactérias na secreção láctea durante a evolução do período seco;

- verificou-se que em 59,37\% (19/32) dos quartos mamários foi possíveloisolamento da mesma bactéria na secreção láctea durante a evolução do período seco; - observou-se que em 40,63\% (13/32) dos quartos mamários ocorria a eliminação da bactéria durante a evolução do período seco, porém em 61,54\% (8/13) desses quartos ocorria re-infecção da mama, pois outro tipo de bactéria passou a ser isolada na secreçãoláctea.

Os dados obtidos na literatura consultada indicam similaridade com as afirmações anteriormente apresentadas, ou seja, durante o período seco podem ocorrer novas infecções, cura das infecções existente e reinfecções (BROWNING et al., 1990; McDONALD, 1982; NAtZKE et al., 1975; NeAve et al., 1950; Oliver et al., 1956).

\section{CONCLUSÕES}

Entre a última ordenha antes do seu início e o $45^{\circ}$ dia do período seco não houve diferenças estatísticas entre as frequências de isolamentos bacterianos, enquanto o percentual de mamas com isolamento bacteriano no retorno da lactação foi menor do que o encontrado durante o processo de secagem da glândula mamária. A análise da dinâmica da população bacteriana durante o período seco permitiu afirmar que a taxa de cura das infecções existentes foi igual a $40,63 \%$, enquanto as taxa de novas infecções e reinfecções durante o período seco foram, respectivamente, iguais a 66,67 e $61,54 \%$.

\section{REFERÊNCIAS}

ARAÚJO, W.P. Constituição físico-química, celular e microbiológica de leites tipo A, B e Especial colhidos de vacas criadas no estado de São Paulo. contribuição à semiologia da glândula mamária. 1994. 54f. Tese (Livre Docência) Faculdade de Medicina Veterinária e Zootecnia, Universidade de São Paulo, São Paulo, 1994.

BERQUO, E.;SOUZA, J.M.P.; GOTTLIEB, S.L.D. Bioestatística. São Paulo: CPU, 1981. 350p.

BERRY, E.A.; HILLERTON, J.E. The effect of selective dry cow treatment - on new intramammary infections. Journal of Dairy Science, v.85, n.1, p.112-121, 2002.

BIRGEL, E.H. Avaliação das provas utilizadas no diagnóstico da mamite bovina. In: BIRGEL, E.H.; BENESI, F.J. Patologia clínica veterinária. São Paulo: Sociedade Paulista de Medicina Veterinária, 1982. p.177-213.

BIRGEL JUNIOR, E.H. Características físico-químicas, celulares e microbiológicas do leite de bovinos das raças Holandesa, Girolando e Gir, criados no estado de São Paulo. 2006. 335f. Tese (Livre Docência) - Faculdade de Medicina Veterinária e Zootecnia, Universidade de São Paulo, São Paulo, 2006.

BROWNING, J.W.; MEIN, G.A.; BARTON, M.; NICHOLLS, T.J.; BRIGHTLING, P. Effects of antibiotic therapy at drying off on mastitis in the dry period and early lactation. Australian Veterinary Journal, v.67, n.12, p.440-442, 1990.

COSTA, E.O.; MELVILLE, P.A.; RIBEIRO, A.R.; ABE, S.Y.; GABALDI, S.H. Nível de infecção intramamária no período seco em propriedades com e sem tratamento de vacas secas. In: CONGRESSO BRASILEIRO DE MEDICINA VETERINÁRIA, 23., 1994, Olinda. Anais. Olinda: [s.n.], 1994. p.233.

COSTA, E.O.; GARINO JUNIOR, F.; WATANABE, E.T.; SILVA, J.A.B.; RIBEIRO, A.R.; HORIUTI, A.M. Patógenos de mastite bovina isolados de glândulas mamárias negativas aos testes de tamis e CMT. Revista do Núcleo de Apoio à Pesquisa em Glândula Mamária e Produção Leiteira - NAPGAMA, v.4, n.2, p.12-16, 2001. 
COWAN, S.;STEEL, K.J. Cowan and Steel's manual for identification of medical bacteria. 2nd.ed. Cambridge: University Press, 1985p.

CUMMINS, K.A.; MCCASKEY, T.A. Multiple infusions of cloxacilina for treatment of mastitis during the dry period. Journal of Dairy Science, v.70, n.12, p.2658-2665, 1987.

DELLA LIBERA, A.M.M.P. Características físico-químicas e microbiológicas do leite de vacas com alta contagem de células somáticas. 1998. 97f. Dissertação (Mestrado em Medicina Veterinária) - Faculdade de Medicina Veterinária e Zootecnia, Universidade de São Paulo, São Paulo, 1998.

EBERHART, R.J. New infections in the dry period. In: ANNUAL MEETING OF NATIONAL MASTITIS COUNCIL, 21., 1982, Louisville, Proceedings. Kentucky: N.M.C, 1982. p.101-111.

FOLEY, R.C.; BATH, D.L.; DICKINSON, F.N.; TUCKER, H.A. Dairy Cattle: principles, practices, problems, profits. Philadelphia: Lea \& Febiger, 1972. 693p.

HOLT, J.G.; KRIEG, R.N.; SNEATH, P.H.A.; STALEY, J.T.; WILLIAMS, S.T. Bergey's manual ${ }^{\circledR}$ of determinative bacteriology. 9th.ed. Baltimore: Williams e Wilkins, 1994.

LENNETTE, E.H. (Ed.). Manual of clinical microbiology. 4th.ed. Washington, D.C.: American Society for Microbiology, 1985. 1149p.

MCDONALD, J.S.; ANDERSON, A.J. Total and differntial somatic cell counts in secretions from noninfected bovine mammary glands: The Early nonlactating period. American Journal of Veterinary Research, v.42, n.8, p.1360-1365, 1981.

MCDONALD, J.S. Experimental infection of the bovine mammary glands during the dry period. In: ANNUAL MEETING OF NATIONAL MASTITIS COUNCIL, 21., 1982, Louisville, Proceedings. Kentucky: N.M.C, 1982. p.112-124.
NATZKE, R.P.; EVERETT, R.W.; BRAY, D.R. Effect of drying off practices on mastitis infection. Journal of Dairy Science, v.58, n.12, p.1828-1835, 1975.

NATZKE, R.P. Elements of mastitis control. Journal of Dairy Science, v.64, n.6, p.1431-1442, 1981.

NEAVE, F.K.; DODD, F.H.; HENRIQUES, E. Udder infections in the dry period I. Journal of Dairy Research, v.17, n.1, p.37-49, 1950.

OLIVER, J.; DODD, F.H; NEAVE, F.K.; LEE, J.M. Udder infections in the dry period II. The effect of withdrawing secretion from the dry udder on the incidence of infection. Journal of Dairy Research, v.23, n.1, p.194-196, 1956.

OLIVER, S.P.; SORDILLO, L.M. Udder health in the periparturient period. Journal of Dairy Science, v.71, n.9, p.2584-2606, 1988.

PRIETO, H.P. Influência dos processos de interrupção da lactação na ocorrência de mastite bovina. 1993. 73p. Dissertação (Mestrado em Medicina Veterinária) - Faculdade de Medicina Veterinária e Zootecnia, Universidade de São Paulo, São Paulo, 1993.

RINDSIG, R.B.; RODEWALD, R.G.; SMITH, A.R.; SPAHR, S.L. Complete versus selective dry cow therapy for mastitis control. Journal of Dairy Science, v.61, n.10, p.1483-1497, 1978.

SMITH, K.L.; TODHUNTER, D.A. The physiology of mammary glands during the dry period and the relationship to infection. In: ANNUAL MEETING OF NATIONAL MASTITIS COUNCIL, 21., 1982, Louisville, Proceedings. Kentucky: N.M.C., 1982. p.87-100.

ZADOKS, R.N.; ALLORE, H.G.; BARKEMA, H.W. Cow and quarter level risk factors for Streptococcus uberis and Staphylococcus aureus mastitis. Journal of Dairy Science, v.84, n.12, p.2649-2663, 2001.

Receido em 15/8/08

Aceito em 6/3/09 